\title{
The Mid-Atlantic Regional Assessment: motivation and approach
}

\author{
A. Fisher ${ }^{1, *}$, R. Neff ${ }^{2}$, E. J . Barron ${ }^{3}$ \\ ${ }^{1}$ Department of Agricultural Economics and Rural Sociology, ${ }^{2}$ Department of G eography, and \\ ${ }^{3}$ Earth Systems Science C enter, The Pennsylvania State University, University Park, Pennsylvania 16802, USA
}

\begin{abstract}
The US Global Change Research Program has initiated a National Assessment of potential impacts from climate change. This paper summarizes the National Assessment process, and the Mid-Atlantic Regional Assessment (MARA) as an example of how the process is being implemented. At the national level, 5 sectoral working groups are assessing impacts on agriculture, forests, freshwater resources, coastal zones and human health. Because different areas of the country will experience impacts to differing degrees, regional assessments simultaneously are examining sectoral impacts identified as likely to be most important within each of 18 US regions. An independent panel of experts, the National Assessment Synthesis Team, is synthesizing the sectoral and regional findings for a national report that provides regional texture. The approach adopted for the MARA is described in the context of the National Assessment process. Such a complex undertaking relies on multiple extensive data sets. The MARA approach to managing the diverse data sets is outlined as a potential guide for similar efforts.
\end{abstract}

KEY WORDS: Climate change impacts $\cdot$ National assessment $\cdot$ Regional assessment $\cdot$ Data management

\section{THE FIRST NATIONAL ASSESSMENT}

The US Congress noted scientific findings that 'industrial, agricultural, and other human activities, coupled with an expanding world population, are contributing to processes of global change that may significantly alter the Earth habitat within a few generations' as a basis for the Global Change Research Act of 1990 (1990). This Act requires the US Global Change Research Program (USGCRP) to report to the President and Congress, at least every $4 \mathrm{yr}$, on the potential national impacts of global change.

A mong the many potential causes of global change, climate change poses especially interesting challenges at the national level. The best-known assessments of potential impacts from climate variability and change have taken a global perspective, looking at regions the size of continents (e.g. Watson et al. 1996). Descriptions of impacts for large, multi-country regions may make it difficult for any particular country's policy

*E-mail: fisherann@psu.edu makers to determine the extent of threat for their country and what might be done to adapt effectively. In 1997 such considerations led the N ational Science and Technology Council (NSTC) Subcommittee on Global Change Research (SGCR), which coordinates the USGCRP, to initiate the First US National Assessment. Its focus is on the local, regional and national implications of climate variability and climate change. The organizational structure for this assessment is shown in Fig. 1 and described below.

Some of the processes regulating vulnerability to climate change operate at local scales and thus the impacts of climate change will differ across regions. Such differences could be missed in aggregate national and global studies, so the USGCRP has been collaborating with federal agencies (represented in the National Assessment Working Group, NAWG) to sponsor 18 regional assessments that span the nation and its territories (Fig. 2). The USGCRP also is sponsoring 5 nation-wide assessments of the following crosscutting sectors: coastal areas and marine resources, freshwater, agriculture, forests and human health. The National A ssessment also includes a working group for 


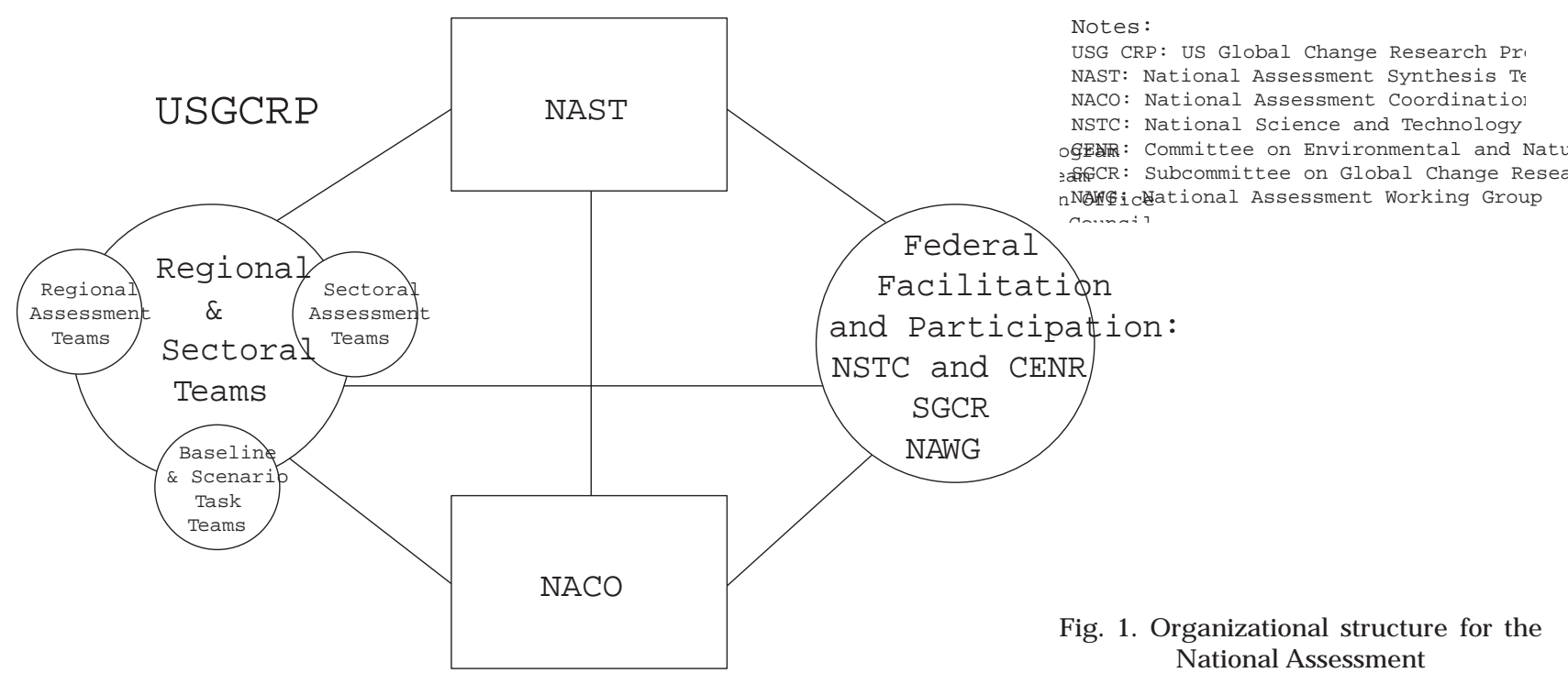

Native Peoples/Native Homelands. The overarching goal is to provide scientific information useful to society by identifying how people and their surroundings will be affected by climate change, how individuals and communities can take advantage of opportunities and reduce vulnerabilities resulting from climate change, and what additional information and research are needed to improve decisions related to impacts from climate change. The assessments are challenging because of the uncertainties in projecting climate change as well as how society will evolve-with or without climate change. They are unique because of their reliance on multi-disciplinary integrated approaches and substantial stakeholder participation. The integrated approach used for one of these assessments-the Mid-Atlantic Regional Assessment (MARA) - is introduced in Section 2 of this paper; illustrations of its application appear in several other articles in this Special. Stakeholder participation is described in O'Connor et al. (2000, in this issue).

The SGCR set up an interdisciplinary National Assessment Synthesis Team (NAST), whose members represent academia, government and business. The NAST is summarizing the potential national impacts from changes in climate and climate variability. All of these assessments are expected to integrate, evaluate and interpret their findings, and discuss the uncertainties associated with the findings.

Fig. 1 shows the structure established to facilitate interaction among the NAST and the regional and sectoral teams. The National Assessment Coordination Office (NACO) provides support to the NAST as well as coordination among the federal participants and the regional and sectoral teams. Implementation includes a broad range of activities. For example, about 400 people attended the November 1997 US Climate Forum, which was designed to gather input from experts and stakeholders about the scope for a national assessment. The teams planning and working on the national, regional and sectoral assessments have gathered annually for in-person sharing of methodologies, data and insights. The NACO also sets up more frequent meetings for the NAST. The short period for planning and executing the suite of assessments means that results from some of the regional and sectoral assessments will not be available in time for the NAST to use in its synthesis report, which is due to Congress in the year 2000. However, frequent interaction among the assessment teams will allow the NAST report to convey important differences across regions and sectors.

The NACO also maintains the National Assessment web-site (http://www.nacc.usgcrp.gov). Because some stakeholders prefer more traditional communication modes, the NACO publishes the newsletter Acclimations in a paper version as well as on the web-site. A nother example of coordination is to provide models, data and projections so that there will be comparability across the regional and sectoral assessments. Based on input from the NAST and the regional and sectoral assessment teams, the NACO and the federal participants have provided socioeconomic projections to the year 2050 at a county level, for a range of potential futures that might occur in the absence of climate change (NPA Data Services, Inc. 1999). They have provided historic climatology for the period 1895 to 1993. Their general circulation models simulate from 1895 to 2100 , thus overlapping the historical climatology. Extensions into the future assume a $1 \% \mathrm{yr}^{-1}$ increase in greenhouse gas emissions, both with and without aerosols. Simulations for carbon dioxide stabilization at 


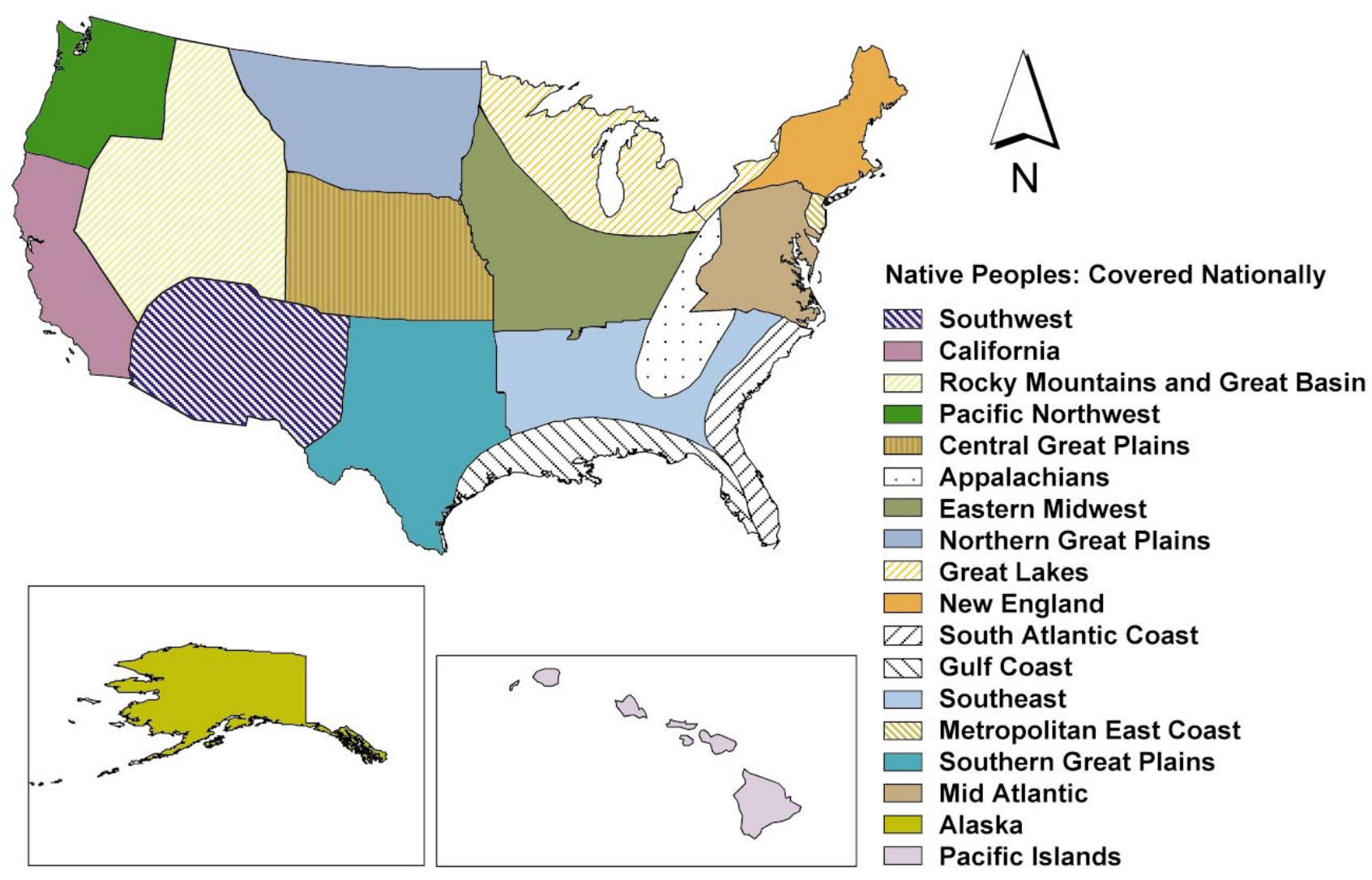

Fig. 2. US National Assessment Regions

550 ppm also are included (Polsky et al. 2000, in this issue, provide more detail on the climate models). Assessment teams are encouraged to use additional models and data applicable for their regions or sectors, and to consider the 'what if' implications of extreme climate or socioeconomic conditions.

The assessments are intended to be open, comprehensive and iterative and to link scientific research to stakeholders' needs, all in the context of scientific excellence (Dresler 1999). The assessment process is intended to provide scientific information that will enable sound decisions; to foster partnerships among stakeholders, agencies and assessment teams; to build stakeholder networks; and to refine the US research agenda related to potential impacts from climate change.

The Intergovernmental Panel on Climate Change (IPCC) is working on its third (global) assessment simultaneously with the US National Assessment activities. There is substantial informal interaction among individuals responsible for different components of the National and IPCC assessments. These interactions include sharing of models, data and perspectives.

The first US National Assessment is an ambitious undertaking for several reasons. First, the climaterelated issues differ across sectors and regions, calling for differing mixes of disciplines across the assess- ments. Individuals have to communicate effectively among the disciplines represented within their own team, as well as across assessment teams. The emphasis on stakeholder participation gives more impetus to the need for effective communication. Second, the simultaneous nature of the work being done by distinct sectoral, regional and national teams creates challenges so that output from one team will be timely as input for another. Third, the NAWG has been charged with developing a plan for assessments after the first US National Assessment. The form and scope of subsequent assessments will be influenced by the success of the first one.

\section{REGIONAL ASSESSMENT APPROACH}

The M id-Atlantic Regional Assessment (MARA) provides an example of how assessment teams can examine potential regional impacts from climate variability and change. This section introduces the M ARA approach, and Section 3 summarizes its process.

An interdisciplinary Pennsylvania State University (Penn State) team is leading the first M ARA of climate change impacts. The core team includes 13 faculty members, 6 post-doctoral or associate researchers, 
24 graduate assistants and 10 undergraduate interns. The core team's expertise is being expanded by substantive collaboration with another 14 researchers at Penn State and other universities plus 4 at private organizations and 4 in government. Substantial input and feedback also come from the MARA Advisory Committee (O'Connor et al. 2000).

Fig. 3 shows that the Mid-Atlantic Region (MAR) includes all or parts of 8 states (N ew York, N ew J ersey, Pennsylvania, Delaware, M aryland, West Virginia, Virginia and North Carolina) and the District of Columbia. A combination of political and practical factors influenced the choice of boundaries for the MAR.

Four questions guide all of the National Assessment components, with tailoring for whether the scope is national, regional or sectoral. For the MARA, these questions are: (1) What are the region's current environmental stresses and issues that provide context for impacts from climate change? (2) How could climate change and variability exacerbate or ameliorate these stresses, or create new ones? (3) What actions could increase the region's resiliency to climate variability, reducing negative impacts and taking advantage of opportunities created by climate change? (4) What are

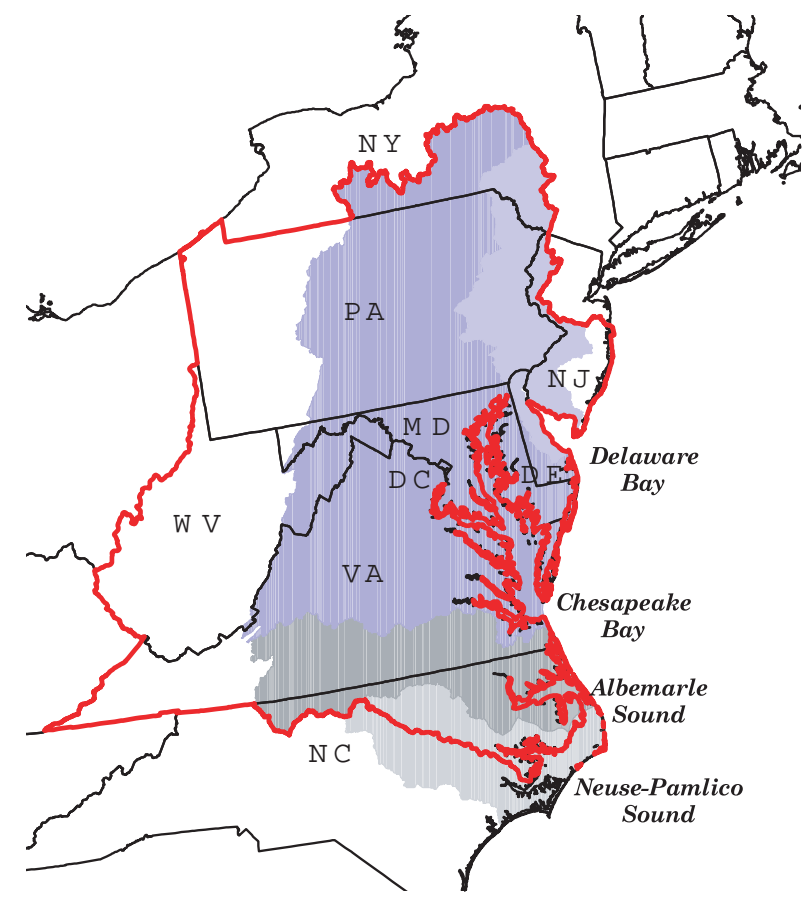

Boundaries of the Mid-Atlantic Region

State Boundaries

Delaware River Basin

Chesapeake Bay Basin

Chowan-Roanoake River Basin

Neuse-Pamlico River Basin

Fig. 3. Mid-Atlantic Region the short-term and long-term priorities for new information and research to better answer Questions (1) and (2) and to evaluate adaptation options?

Penn State's approach to these questions is based on a framework developed by its Center for Integrated Regional Assessment (CIRA) (Knight 2000) and shown in Fig. 4. Assessment can begin at any point in the diagram; the logic follows a continuous loop. For example, the assessment could (1) start with causes, (2) examine how the causes lead to climate changes, (3) project the biophysical and socioeconomic consequences of these climate changes and (4) project human responses to the consequences - and then use an iterative approach for examining the extent to which those human responses become causes. The framework accommodates increasingly complex quantitative and qualitative analyses for important components. It also accounts for hierarchical relationships among different scales. The MARA is based on the assumption that the causes of climate change are mainly outside the region, but that climate change could engender important interactions among the ecological and physical responses within the region. However, because human responses include actions that in turn generate climate change at a national or global level, the National Assessment needs to account for the aggregate effects of similar actions across regions.

An example of other regional assessment efforts is the CLIMPACTS system. This integrated model has 3 main components (Kenny et al. 1995; http://www. waikato.ac.nz/igci/projects/climpacts/system.htm, accessed: 4 November 1999). Its global climate model (MAGICC) can generate greenhouse gas emissions and the implied global temperature changes (to the year 2100). A regional-scale climate model/scenario generator then uses historical climate data in combination with patterns of temperature and rainfall change derived from MAGICC and downscaled for New Zealand. The results are fed into biophysical sectoral impact models. So far, these have been developed for agricultural production in New Zealand (kiwifruit, maize, sweetcorn, paspalum, kikuyu, wheat and barley).

Section 1 mentioned that the NACO has coordinated the provision of recommended specific global climate models (GCMs) and socioeconomic projections to ensure some comparability among the regional and sectoral assessments. In addition, Penn State is using its own empirical downscaling and nested GCM /mesoscale models, which provide finer resolution as appropriate for regional assessment (Crane et al. 2000). Penn State also has developed an approach for designing socioeconomic/ecological scenarios likely to yield boundaries for both beneficial and detrimental impacts (A bler et al. 2000). 


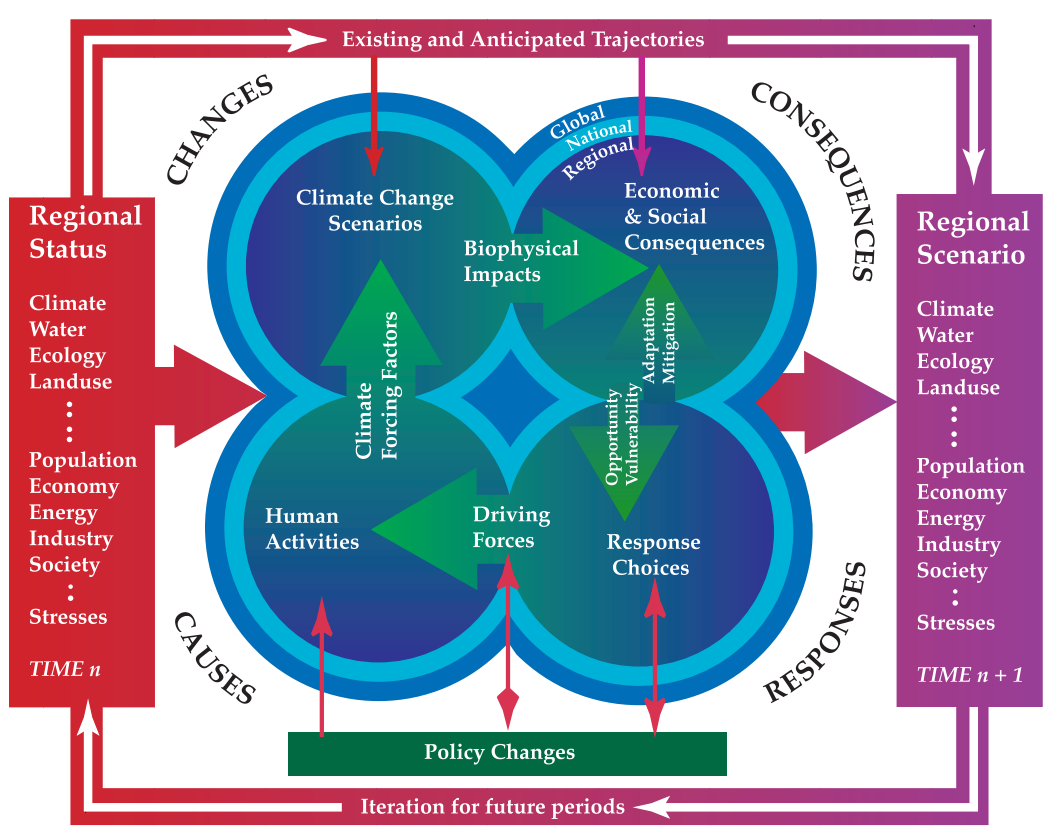

Fig. 4. Framework for Integrated Regional Assessment of Global Climate Change recreation and about human health impacts.

Another step in this dialog was a J une 1998 researchers' meeting to explore questions raised during the September 1997 workshop and identify available databases and current research useful for the MARA. At an October 1998 event, the MARA Advisory Committee provided input on the scope for the region's first assessment of climate change impacts. This open process showed the need to address the 5 major topics being emphasized in the National Assessment-forests, agriculture, freshwater resources, coastal zones and human health-as well as crosscutting ecosystems issues.

Dialog has continued through frequent interaction with the MARA Advisory Committee (O'Connor et al. 2000). In addition to periodic mailings and requests for feedback, members met in May 1999 to react to initial findings and suggest strategies for disseminating results to potential users.

Building on these inputs, the MARA team meets every third week and has more frequent subgroup meetings. A draft overview report (Fisher at al. 1999b) summarizes baseline conditions and how human and natural systems might be affected by climate change, using the integrated assessment framework and case studies to illustrate important impacts. It brings together information about diverse beneficial and detrimental impacts into a picture of the effects on the region as a whole. The draft report is undergoing a formal peer review. The MARA team will document their responses to the peer-review comments; the revised overview report will be printed as one of a set of companion documents to the National Assessment report. The papers in this Special provide a more technical summary of components in the overview draft. Additional details also are available in Fisher et al. (1999c), and will be forthcoming in its peerreviewed 'foundation' revision. Work is continuing for a second year of this initial MARA, with periodic updates posted at the MARA web-site (http://www.essc. psu.edu/mara). Team members will continue to present results at professional meetings and submit journal manuscripts for peer review. The final products will serve as a baseline for future assessments, expected to be conducted on a $4 \mathrm{yr}$ cycle. They also are expected to serve as examples for others who wish to conduct regional assessments. 
Table 1. M ajor data sets being used for the Mid-Atlantic Regional Assessment. CCC: Canadian Climate Centre; GIS: Geographic Information System; MRLC: Multi-Resolution Land Characteristics; NPA: NPA Data Services, Inc.; USDA: US Department of Agriculture; USEPA: US Environmental Protection Agency; USGS: US Geological Survey; VEMAP: Vegetation/Ecosystem Modeling and Analysis Project

\begin{tabular}{|c|c|c|c|}
\hline Data set & Source & Groups using data set & Location in web-ring \\
\hline \multirow{2}{*}{$\begin{array}{l}\text { GIS coverage and map of MARA boundaries } \\
\text { GIS coverage, map and list of } \\
\text { counties in the MARA region }\end{array}$} & Internal & All & Water site \\
\hline & Internal & All & Water site \\
\hline $\begin{array}{l}\text { GIS coverage, map and list of counties } \\
\text { in subregions of the MARA region }\end{array}$ & Internal & All & Water site \\
\hline Climate scenarios (CCC and Hadley models) & VMAP & All & Climate site \\
\hline M RLC land use/cover gridded data & USGS & Agriculture, forestry, ecosystems & Agriculture site \\
\hline Stream flow & USGS & Water, coastal & Water site \\
\hline Census data & $\begin{array}{l}\text { US Bureau of } \\
\text { the Census }\end{array}$ & Health, water, coastal & Water site \\
\hline NPA economic and demographic projections & NPA & All & Water site \\
\hline GIS coverage of major land resource areas' boundaries & USGS & Agriculture, forestry, ecosystems & Agriculture site \\
\hline GIS coverage of US EPA eco-regions & USEPA & Agriculture, forestry, ecosystems & Agriculture site \\
\hline Soils data for the Mid-Atlantic Region & USDA & Agriculture, water & Agriculture site \\
\hline Digital elevation model for Mid-Atlantic Region & USEPA & Coastal, ecosystems & To be determined \\
\hline
\end{tabular}

\section{DATA SOURCES AND DATA MANAGEMENT}

As with any regional assessment, MARA is datadriven. The many large data sets (see Table 1 ) and the many people involved in the assessment made it necessary to find an efficient way to store, distribute and verify the quality of these data sets. It also is crucial that the data used by different groups be comparable, i.e. if one group is using a particular data set to describe population, it should be the same population data set that is being used by other groups. Personnel and data change over time, so having a central datastorage structure is essential for long-term continuity of the assessment. Thus, the MARA team decided to make certain data sets available on the World Wide Web to facilitate the transfer of data among working groups and researchers.

The human resources required for a truly centralized web-site containing all the data sets used by the MARA team were not available during the assessment's first year, so a ring of related web-sites was developed over time (Fig. 5). M ost working groups created and maintained their own web-sites. As the ring began to evolve, team members found it more difficult and time consuming to locate specific data sets. As more data sets were added, maintenance of the webring became increasingly problematic due to a lack of human resources. The result was that some working groups' web-sites were developed more quickly than others, and some did not provide all the data sets that are available. These shortcomings are being addressed during the MARA's second year. Data sets are being moved to a new centrally managed web-site. The revised mission of each working group's web-site is to share draft documents and preliminary results within the MARA team. As the assessment process continues, the web-ring will have a larger role in data and information dissemination, both within the MARA team and to stakeholders and other interested parties.

\section{MOTIVATION FOR READING MORE}

This introductory paper provides background about the National Assessment needs and process, and why regional and sectoral assessments are being conducted. It summarizes the conceptual framework that has guided preliminary MARA activities, and that will guide refinement efforts during the assessment's sec-

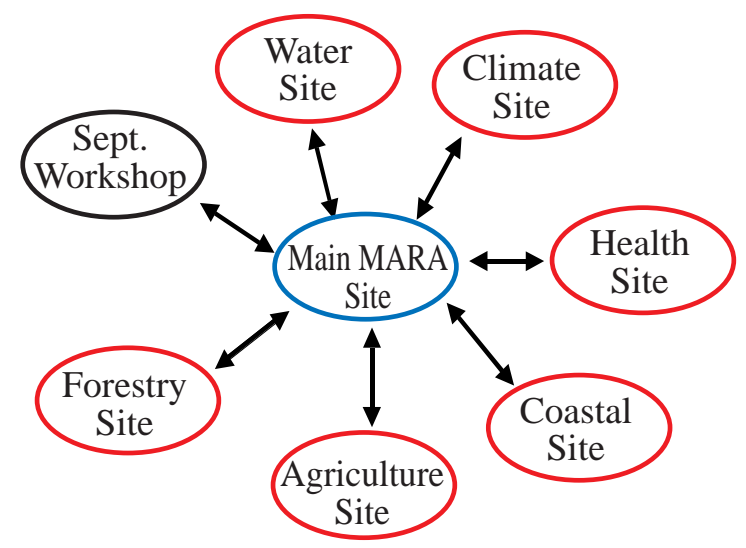

Fig. 5. Schematic of MARA's internal web-ring. A black outline signifies a site to which access is unrestricted; blue signifies partially restricted access; red signifies very restricted access 
ond year. It also addresses the crucial issue of how to manage and provide access to diverse data sets and interim drafts for a large, evolving, multi-disciplinary team. The next paper in this Special (Polsky et al. 2000) describes the MAR in terms of its geography and trends and projections in population, income and climate. The following paper (Rose et al. 2000) explains the role of economic analysis in integrated regional assessment. This suite of 3 papers sets the stage for the sectoral assessments reported in the following 6 papers.

Despite many uncertainties, the MARA shows that the region's economy is likely to be reasonably resilient to climate variability and change. On the other hand, these papers show that climate change poses diverse and potentially large risks to the region's ecosystems - which already show signs of stress for many reasons. Both positive and negative impacts can be expected-with benefits likely to be fewer and smaller than damages. The impacts will make some of the region's citizens better off and others worse off. These distributional effects, in concert with overall economic resilience and pressure on ecosystems, form the basis for taking advantage of opportunities created by climate change and for coping with its damages. The final paper in this Special synthesizes the findings from these papers, identifying the most important impacts and their uncertainties. The entire set of papers is intended to demonstrate how others can build on the MARA experience.

Acknowledgements. This research is supported by US Environmental Protection Agency Cooperative Agreement No. 826554 and by Pennsylvania State University. The views presented here are the authors', and should not be attributed to the sponsors. The authors appreciate the constructive comments of 2 anonymous reviewers.

\section{LITERATURE CITED}

Abler DG, Shortle J S, Rose A, Oladosu G (2000) Characterizing regional economic impacts and responses to climate change. Global Planet Change (in press)

Crane RG, Yarnal B, Barron EJ, Hewitson BC (2000) Scale interactions and regional climate: examples from the Susquehanna River basin. Human Ecol Risk Assess (in press)
Dresler P (1999) US National Assessment: the potential consequences of climate variability and change. MARA Advisory Committee Meeting, May 2-3, 1999 Pennsylvania State University, University Park (accessed: 2 February 1999); available at http://www.essc.psu.edu/mara/events/ advisory_May99/Dresler/index.htm

Fisher A, Barron E, Yarnal B, Knight CG, Shortle J (1999a) Climate change impacts in the Mid-Atlantic Region-a workshop report (to the US Environmental Protection Agency, Washington, DC, under cooperative agreements CR 826554 and CR 824369). Pennsylvania State University, University Park

Fisher A, and 12 others (1999b) Preparing for a changing climate: the potential consequences of climate variability and change-Mid-Atlantic draft, prepared for USGCRP First National Assessment, sponsored by US Environmental Protection Agency, Cooperative Agreement CR 826554. Pennsylvania State University, University Park

Fisher A, and 12 others (1999c) M id-Atlantic Regional Assessment (MARA) draft preliminary report on impacts from climate change. Prepared for USGCRP First National Assessment, sponsored by US Environmental Protection Agency, Cooperative Agreement CR 826554-01 (accessed: 1 October 1999); available at http://www.essc.psu.edu/ mara/data.html \#draft_documents

Global Change Research Program Act of 1990 (1990) US Public Law 101-606 (November 16, 1990). 104 Stat. 3096-3104

Kenny GJ , Warrick R, M itchell ND, Mullan AB, Salinger MJ (1995) CLIM PACTS: an integrated model for assessment of the effects of climate change on the New Zealand environment. J Biogeogr 22:883-895

Knight CG (2000) Regional assessment. Oxford encyclopedia of global change. Oxford University Press, New York (in press)

NPA Data Services, Inc (1999) Regional economic projections series, Washington, DC

O'Connor RE, Anderson PJ , Fisher A, Bord RJ (2000) Stakeholder involvement in climate assessment: bridging the gap between scientific research and the public. Clim Res 14:255-260

Polsky C, Allard J, Currit N, Crane R, Yarnal B (2000) The Mid-Atlantic Region and its climate: past, present, and future. Clim Res 14:161-173

Rose A, Cao Y, Oladosu G (2000) Simulating the economic impacts of climate change the Mid-Atlantic Region. Clim Res 14:175-183

Watson RT, Zinyowera MC, Moss RH (eds) (1996) Climate change 1995: Impacts, adaptations and mitigation of climate change: Scientific, technical analysis, Contributions of Working Group II to the Second Assessment report of the Intergovernmental Panel on Climate Change. Cambridge University Press, New York 